УДК 536.27

\title{
ДОСЛІДЖЕННЯ ТЕПЛООБМІННИКА ІЗ ЗАДАНИМ ЗАКОНОМ РОЗПОДІЛЕННЯ КОЕФІЦІЄНТІВ ТЕПЛОПЕРЕДАЧІ ВЗДОВЖ ПОВЕРХНІ ТЕПЛООБМІНУ
}

\section{Свтушенко О.В.}

Інститут технічної теплофізики НАН Украӥни, вул. Желябова, 2а, Київ, 03680, Украӥна

Розглянуто теплообмінник, у якого коефіцієнт теплопередачі змінюється вздовж теплопередавальної поверхні за законом нормального розподілення Гауса. На базі даного теплообмінника представлений вивід основних рівнянь та виконані розрахунки температурного профілю, а також профілю теплового потоку та ефективності теплопередавальної поверхні.
Рассмотрен теплообменник, у которого коэффициент теплопередачи изменяется вдоль теплопередающей поверхности по закону нормального распределения Гаусса. На базе данного теплообменника, представлен вывод основных уравнений и выполнены расчеты температурного профиля, а также профиля теплового потока и эффективности теплопередающей поверхности.
The paper considered heat exchanger in which the heat transfer coefficient varies along the heat transfer surface under the law of the normal Gaussian distribution. On the basis of the present heat exchanger is presented basic equations derivation and calculations of the temperature profile and the profile of the heat flow and efficiency of the heat transfer surface.

Бібл. 11, табл. 1, рис. 4.

Ключові слова: гетерогенний теплообмінник, закон нормального розподілення Гауса, коефіцієнт теплопередачі.

$C$ - витратна теплоємність;

$F$ - площа теплообміну;

$f$ - густина розподілення;

$G$ - витрата;

$k$ - коефіцієнт теплопередачі;

$Q$ - кількість теплоти;

$t$ - температура;

$\alpha$ - коефіцієнт тепловіддачі;

$\delta$ - товщина;

\section{Постановка задачі}

Теплообмінники $€$ найбільш поширеними i значними елементами (апаратами) складних теплотехнологій в будь-яких галузях промисловості (енергетичній, хімічній, металургійній та інших) та перекривають широкий діапазон пристроїв від масштабних енергетичних ядерних реакторів та парогенераторів теплових електростанцій [1-4] до мікроканальних теплообмінників - новітньої технології хімічних і теплових мікросистем [5-7]. Проблема теплообмінну в енерготехніці обговорюється так само гостро, як і проблема $\lambda$ - коефіцієнт теплопровідності;

$\sigma-$ середньоквадратичне відхилення.

Індекси нижні:

$\min$ - мінімальний;

max - максимальний;

1 - гарячий теплоносій;

2 - холодний теплоносій;

in - початковий параметр теплоносія;

out - кінцевий параметр теплоносія.

економії енергоресурсів. Системи опалення та кондиціонування сучасного житла, радіаторні системи автомобілів, системи тепловідводу в електроніці та комп'ютерній техніці немислимі без ефективних теплообмінників. Тому питання створення нових ефективних теплообмінників залишається актуальним, не звертаючи увагу на широке різноманіття існуючих теплообмінних поверхонь.

В даній роботі розглядається задача теплообміну через теплопередавальну поверхню, у якої коефіцієнт теплопередачі змінюється вздовж поверхні $F$ від $k_{\min }$ до $k_{\max }$. На практиці, 
при розрахунках температурного розподілу теплообмінника $t(F)$ користуються середньоінтегральною величиною коефіцієнта (функціі) теплопередачі в межах $[0, F]$, яка визначається за формулою:

$\bar{k}=\frac{1}{F} \int_{0}^{F} k(F) d F$.

Тут за геометричним змістом під $\bar{k}$ розуміють висоту прямокутника $з$ основою $F$, площа якого дорівнює площі під кривою $k(F)$ на відрізку $[0, F][8]$.

Розглянемо випадок, коли зв' язок коефіцієнтів теплопередачі $\left(k_{\min } \leq k \leq k_{\max }\right)$ зі своїми елементарними площами $d F$ задається математичною моделлю на базі статистичного розподілення Гауса 3 теорії ймовірності [8]:

$$
f(k, \sigma)=\frac{d F}{F_{\text {Total }} d k}=\frac{1}{\sqrt{2 \pi \sigma^{2}}} \exp \left(-\frac{(k-\bar{k})^{2}}{2 \sigma^{2}}\right) .
$$

Тут $F_{\text {Total }}$ - загальна площа теплообмінника; $d F$ - частина площі, коефіцієнт теплопередачі якої лежить в інтервалі між $k$ i $k+d k ; d F / F_{\text {Total }}-$ ймовірність того, що елемент площі має коефіцієнт теплопередачі в межах між $k$ i $k+d k$;

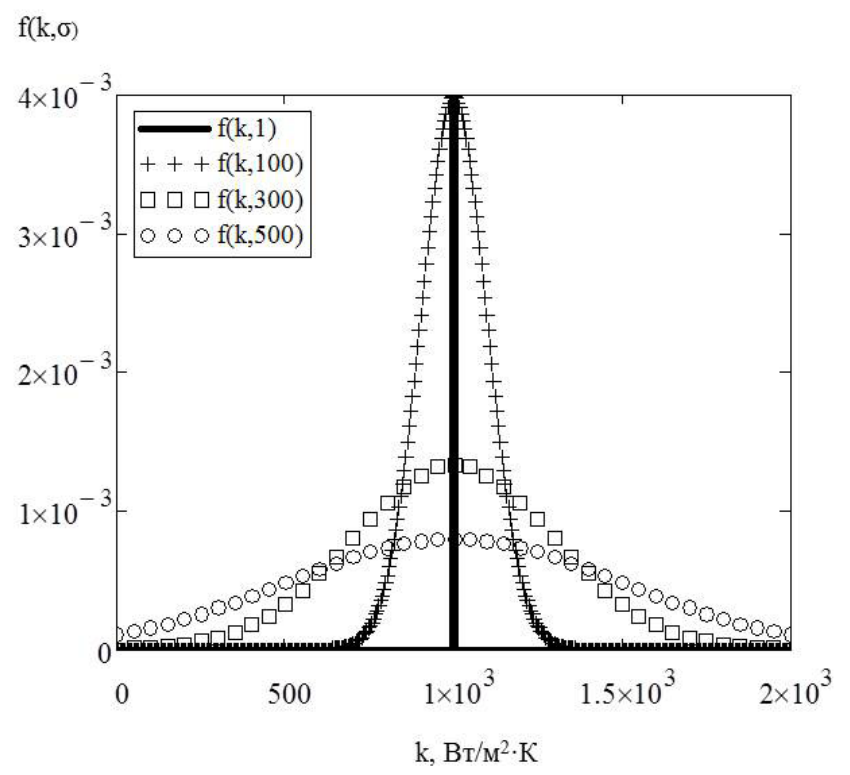

a) $\bar{k}$ - математичне сподівання (середнє значення), медіана і мода розподілення; $\sigma^{2}$ - дисперсія розподілення.

Із (2) очевидно, що

$d F=F_{\text {Total }} f(k, \sigma) d k \Rightarrow F(k, \sigma)=F_{\text {Total }} \int_{k_{\min }}^{k_{\max }} f(k, \sigma) d k$,

тоді функція розподілення коефіцієнтів $k$ вздовж поверхні $F$ приймає вигляд формули:

$k(F)=\frac{\int_{0}^{F(k, \sigma)} k d F}{F(k, \sigma)}$.

Крива розподілення елементів площі по коефіцієнтам теплопередачі за законом Гауса зображена на рисунку 1, $a$. По осі абсцис відкладені коефіцієнти теплопередачі, а по осі ординат $-f(k, \sigma)$ (формула 2$)$. За середнє значення коефіцієнтів теплопередачі приймалася величина $k=1000 \mathrm{Bт} / \mathrm{M}^{2} \cdot$ K. Площа, обмежена кривою розподілу і віссю абсцис, дорівнює одиниці.

Крива розподілення коефіцієнтів теплопередачі в межах заданої поверхні (наприклад, $F=0 \ldots 0,07 \mathrm{M}^{2}$ ) зображена на рисунку $1, \sigma$. По осі абсцис відкладені площі, а по осі ординат $-k(F)$ (формула 4).

$\mathrm{k}, \mathrm{BT} / \mathrm{m}^{2} \cdot \mathrm{K}$

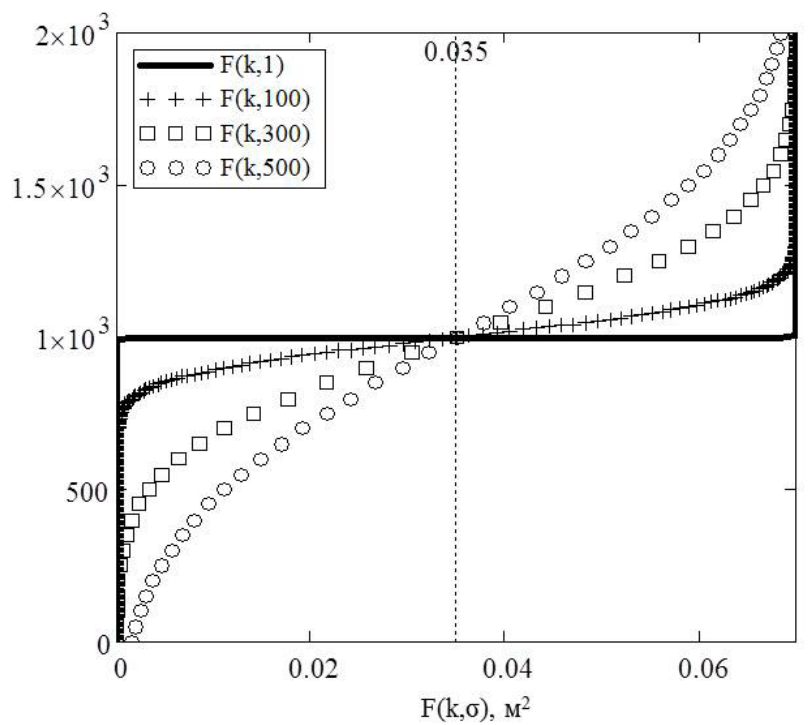

б)

Рис. 1. Характеристика теплообмінника з різною величиною розкиду коефіцієнтів теплопередачі вздовж теплопередавальної поверхні: а) - густина розподілення елементів площі по коефіцієнтам теплопередачі $f(k, \sigma) ;$ б) - функція розподілення коефіцієнтів теп-лопередачі вздовжс теплообмінної площі $F(k, \sigma)$. 
Суцільна лінія на рис. 1 відображає випадок найменшого (майже відсутнього) розкиду величини $k$, тому зображена прямою лінією в точці $k=1000$ паралельною осі ординат на рис. 1, a та осі абсцис на рисунку 1 , б. Це означає, що вздовж всієї поверхні коефіцієнт теплопередачі постійний (інваріантний від поверхні, $d F / d k=0$ ), тому у формулі (1) або (4) його можна винести за знак інтеграла. Зазначимо, що такий варіант характерний для однорідних (гомогенних) поверхонь. Інші лінії, зі символами «+, $\square$, о» на рис. 1, відображають випадок існування розподілення (дисперсії) коефіцієнтів теплопередачі $k$ вздовж певної поверхні $\mathrm{F} \in[0 \ldots 0,07]$. Це означає, що вздовж всієї поверхні коефіцієнт теплопередачі змінюється, $-d F / d k \neq 0$. Форма кривої розподілення коефіцієнтів $k$ визначається величиною розкиду б (в даному прикладі б приймала значення 100,300 та 500).

Слід відзначити, що для усіх випадків площа під кривою на рисунку $1, \sigma$ в межах $\mathrm{F} \in[0 \ldots 0,07]$ однакова і дорівнює добутку $\bar{k} \cdot F$, згідно теореми про середнє значення [8].

Забігаючи наперед, зауважимо, що фізична реалізація такої поверхні можлива за рахунок застосування певної комбінації різних матеріалів зі своїми теплофізичними та геометричними характеристиками (коефіцієнтами теплопередачі $k$ і величиною поверхні $F$ ), які складають загальну площу теплообміну. Надалі таку поверхню будемо називати композитною або гетерогенною, тобто такою, яка складається 3 двох і більше компонентів з чіткою границею розділу між ними.

Отже, основним завданням статті буде розрахунок температурного профілю теплоносіїв вздовж гетерогенної поверхні теплообмінника. Вхідними параметрами є: витратні теплоємності гарячого та холодного теплоносіїв $C_{1}$ i $C_{2}$ (знак перед $C$ вказує напрямок течії, наприклад, при $C_{2}<0$, маємо протитечію); вхідні температури гарячого та холодного теплоносіїв $t_{1 i n}$ i $t_{2 i n}$; середньо-інтегральний коефіцієнт теплопередачі $\bar{k}$; Гаусовий закон розподілення коефіцієнтів теплопередачі вздовж поверхні теплообміну $f(k, \sigma)$; середньо-інтегральна величина ефективності теплообмінника $\overline{E f f}$. Розрахунки проводяться за математичною моделлю складеною нижче.

\section{Математичне моделювання характеру розподілу температур теплоносіїв, теплової енергї та ефективності вздовжс теплообмінної поверхні}

Вихідними параметрами розрахунків будуть: розподіл температур гарячого і холодного теплоносія $\left(t_{1}\right.$ i $\left.t_{2}\right)$, теплової енергії $Q$ та ефективності теплообмінника Eff вздовж гетерогенної теплообмінної поверхні $F$.

Функція розподілення температур $\left(t_{1}, t_{2}\right)$ вздовж теплопередавальної поверхні розраховується за системою рівнянь, отриманої на базі рівняння теплового баланcy $Q(k, \sigma)=C_{1}\left(t_{1 i n}-t_{1}(k, \sigma)\right)=C_{2}\left(t_{2}(k, \sigma)-t_{2 \text { in }}\right) \quad$ та рівняння функції розподілення поверхні $F(k, \sigma)$ (див. формулу 3):

$$
\left\{\begin{array}{l}
t_{1}(k, \sigma)=t_{1 i n}-\frac{Q(k, \sigma)}{C_{1}}, \\
t_{2}(k, \sigma)=t_{1}(k, \sigma)-\Delta t(k, \sigma), . \\
F(k, \sigma)=F_{\text {Total }} \int_{k_{\min }}^{k_{\max }} f(k, \sigma) d k .
\end{array}\right.
$$

Тут $Q(k, \sigma)$ - функція теплової енергії в залежності від $F(k, \sigma)$ розраховується за формулою, отриманою на базі рівняння теплопередачі [1$3,9]$ :

$$
Q(k, \sigma)=\frac{\Delta t(k, \sigma)-\Delta t_{\max }}{\ln \left(\frac{\Delta t(k, \sigma)}{\Delta t_{\max }}\right)} \bar{k}=\frac{\Delta t(k, \sigma)-\Delta t_{\max }}{\ln \left(\frac{\Delta t(k, \sigma)}{\Delta t_{\max }}\right)} \int_{o}^{F(k, \sigma)} k d F .
$$

Тут $\Delta t_{\max }-$ максимальний температурний перепад між гарячим та холодним теплоносієм, $\Delta t_{\max }=t_{1 \text { in }}-t_{2 \text { out }}\left(t_{2 \text { out }}\right.$ - вихідна температура холодного теплоносія). Значення функції локального температурного напору $\Delta t(k, \sigma)$ в кожному перерізі поверхні $F(k, \sigma)$ розраховується за відомою формулою $[1-3,9]$ :

$$
\Delta t(k, \sigma)=\Delta t_{\max } \exp \left[-\left(\frac{1}{C_{1}}+\frac{1}{\left|C_{2}\right|}\right)^{F(k, \sigma)} \int_{0}^{k} k d F\right] .
$$

В свою чергу, повну теплопередавальну площу теплообмінника $F_{\text {Total }}$ розраховуємо за заданою середньо-інтегральною величиною ефективності теплообмінника [9]:

$$
F_{\text {Total }}=\frac{\overline{E f f} \cdot Q_{\max C F}}{\bar{k} \Delta t} .
$$


Ефективність теплообмінника відображає реальну частину теплового потоку в теплообміннику від максимально можливого i, як функція розподілення, визначається за формулою:

$$
\operatorname{Eff}(k, \sigma)=\frac{Q(k, \sigma)}{Q_{\max C F}},
$$

де $Q_{\max C F}-$ максимально досяжний тепловий потік протитечії, розраховується згідно системи рівнянь [9]:

$$
Q_{\max C F}= \begin{cases}C_{1}\left(t_{1 i n}-t_{2 i n}\right), & C_{1}<\left|C_{2}\right|, \\ C_{2}\left(t_{1 i n}-t_{2 i n}\right), & C_{1}>\left|C_{2}\right| .\end{cases}
$$

Слід розуміти, що максимальний тепловий потік гіпотетичного теплообмінника можливий при надзвичайно великій поверхні теплопередачі $\mathrm{F} \rightarrow \infty$. За таких умов вихідна температура гарячого/холодного теплоносія наближається до температури холодного/гарячого теплоносія $\left(t_{1 \text { out }} \rightarrow\right.$ $\left.t_{2 i n}, t_{2 o u t} \rightarrow t_{1 \text { in }}\right)$, а вибір теплоємності при різниці $\left(t_{1 \text { in }}-t_{2 i n}\right)$ визначається умовою, що якщо менше значення $C$ буде у холодного теплоносія $\left(\mathrm{C}_{1}>\left|\mathrm{C}_{2}\right|\right)$, то він нагрівається до вхідної температури гарячого теплоносія, $t_{2 o u t} \rightarrow t_{1 i n}$; якщо менше значення $C$ буде у гарячого теплоносія $\left(\mathrm{C}_{1}>\left|\mathrm{C}_{2}\right|\right)$, то його можна охолодити до температури холодного, $t_{1 \text { out }}-t_{2 \text { in }}[9]$.

При розрахунку по формулі (7) необхідно також відшукати вихідні температури теплоносіїв $t_{1 \text { out }}$ i $t_{2 o u t}$ за заданою величиною ефективності $\frac{\text { lout }}{E f f}$ : $t_{1,2 \text { out }}=t_{1,2 \text { in }}-\frac{\overline{E f f} \cdot Q_{\max C F}}{C_{1,2}}$.

Аналітичне рішення системи рівнянь представлено залежностями:

$$
\begin{aligned}
& t_{1}(k, \sigma)=t_{\text {lin }}-\left(t_{\text {lin }}-t_{2 i n}\right) \frac{1-\exp \left[-\frac{1}{C_{1}}\left(1-\frac{C_{1}}{\left|C_{2}\right|}\right) \int_{0}^{F(k, \sigma)} k d F\right]}{1-\frac{C_{1}}{\left|C_{2}\right|} \exp \left[-\frac{1}{C_{1}}\left(1-\frac{C_{1}}{\left|C_{2}\right|}\right)^{F(k, \sigma)} \int_{0}^{F} k d F\right]} \\
& t_{2}(k, \sigma)=t_{2 i n}+\left(t_{\text {lin }}-t_{\text {2in }}\right) \frac{C_{1}}{\left|C_{2}\right|} \frac{1-\exp \left[-\frac{1}{C_{1}}\left(1-\frac{C_{1}}{\left|C_{2}\right|}\right) \int_{0}^{F(k, \sigma)} k d F\right]}{1-\frac{C_{1}}{\left|C_{2}\right|} \exp \left[-\frac{1}{C_{1}}\left(1-\frac{C_{1}}{\left|C_{2}\right|}\right)^{F(k, \sigma)} \int_{0}^{k} k d F\right]} .
\end{aligned}
$$

При розрахунку функції розподілу температур $t_{12}(k, \sigma)$, теплової енергії $Q(k, \sigma)$ та ефективності $E f f(k, \sigma)$ вздовж гетерогенної теплопередавальної поверхні $F(k, \sigma)$ по формулам (2), (12), (13), (6) і (9) використовувалися такі дані: $C_{1}=50$ Вт/кг $\cdot \mathrm{K}$ та $C_{2}=150 \mathrm{BT} / \mathrm{\kappa} \Gamma \cdot \mathrm{K} ; \bar{k}=1000 \mathrm{BT} / \mathrm{M}^{2} \cdot \mathrm{K} ; 1 \leq \sigma \leq 500$; $t_{1 i n}=100{ }^{\circ} \mathrm{C}$ та $t_{2 i n}=10^{\circ} \mathrm{C} ; \overline{E f f}=0,7$.

Порівняльний результат математичного моделювання кривих зображений на рис. 2. Як видно, розрахункова теплопередавальна площа теплообмінника в межах заданої середньоінтегральної величини ефективності $\overline{E f f}=0,7$ i коефіцієнта теплопередачі $\bar{k}=1000$ складає

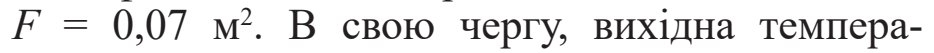
тура гарячого і холодного теплоносія складає $t_{1 \text { out }}=37{ }^{\circ} \mathrm{C}$ i $t_{2 o u t}=31{ }^{\circ} \mathrm{C}$; перепади температур між початковою $\mathrm{i}$ кінцевою температурою обох теплоносіїв $-\Delta t_{1}=63{ }^{\circ} \mathrm{C}$ i $\Delta t_{2}=21{ }^{\circ} \mathrm{C}$. Як і очікувалося, гетерогенний теплообмінник має певний розкид розрахункових даних по температурі, тепловому потоці та ефективності вздовж теплопередавальної поверхні в залежності від величини середньоквадратичного відхилення (дисперсії коефіцієнтів теплопередачі). Наприклад, при $\sigma=500$ (максимальному за умовою задачі значенні) спостерігається найбільше відхилення температурної кривої (лінія «ооо») від середньо-інтегральної (суцільна лінія) характерної для традиційного теплообмінника і складає $\Delta t=20^{\circ} \mathrm{C}$ для гарячого теплоносія і $\Delta t=8{ }^{\circ} \mathrm{C}$ для холодного в перерізі $F=0,07 \mathrm{~m}^{2}$; таким чином, в межах заданої площі теплообміну (розрахованої за величиною ефективності Eff) вдалося знизити/підвищити вихідну температуру гарячого/холодного теплоносія до $t_{1 \text { out }} / t_{2 \text { out }}=17 / 39{ }^{\circ} \mathrm{C}$ і відповідно збільшити перепад температур на вході та виході теплообмінника. Зауважимо, що досягнення вихідної температури гарячого і холодного теплоносія $t_{1 \text { out }}=37^{\circ} \mathrm{C}$ i $t_{2 o u t}=31^{\circ} \mathrm{C}$ для випадку $\sigma=500$ відбувається в межах $F=0,053 \mathrm{M}^{2}$. Те саме спостерігаємо і для величини теплового потоку або, що еквівалентно, ефективності теплообмінника. Зокрема підвищення величини $\sigma$ в 500 раз збільшує тепловий потік (ефективність теплообмінника) практично на 37 \% (iз 3150 Вт до 5000 Вт, див. рис. 2, б). Отже, якщо перед розробником теплообмінника стоїть завдання отримати в межах певної площі (габаритів) заданий температурний перепад (профіль), то вирішенням такої задачі може бути застосування 
композитної (гетерогенної) поверхні.

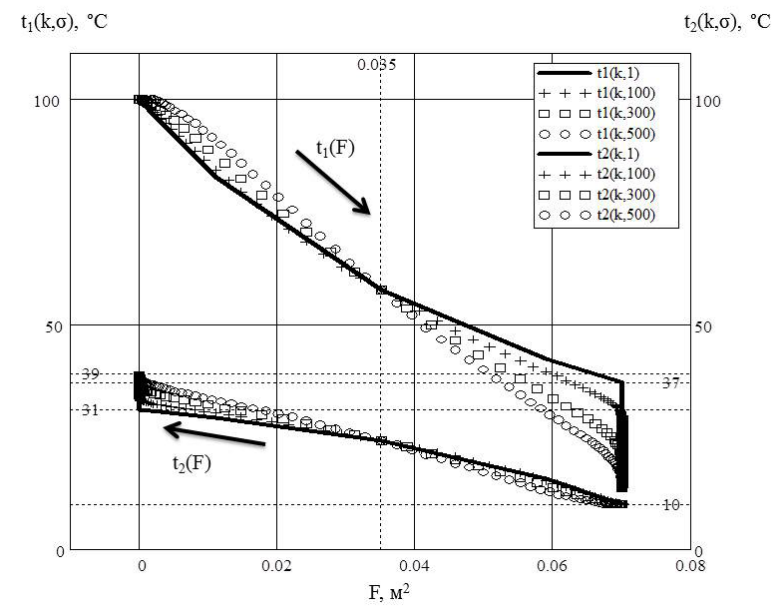

a)

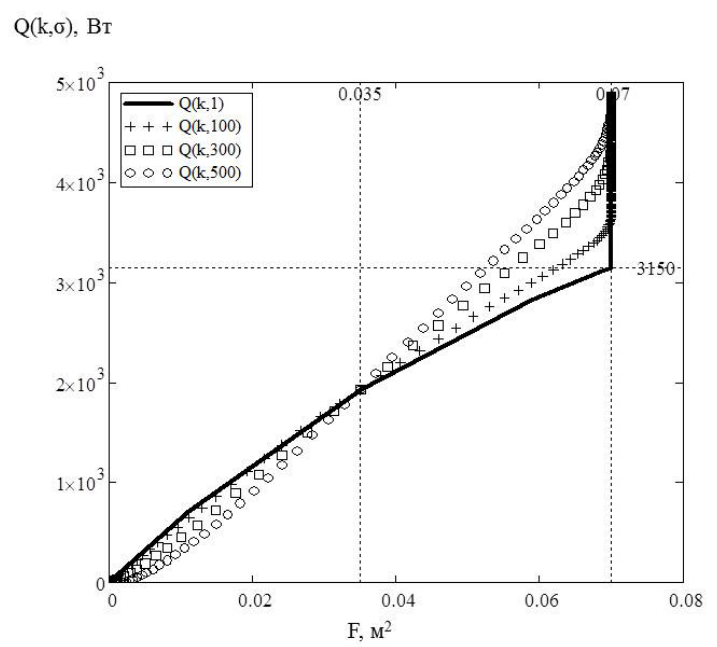

б)

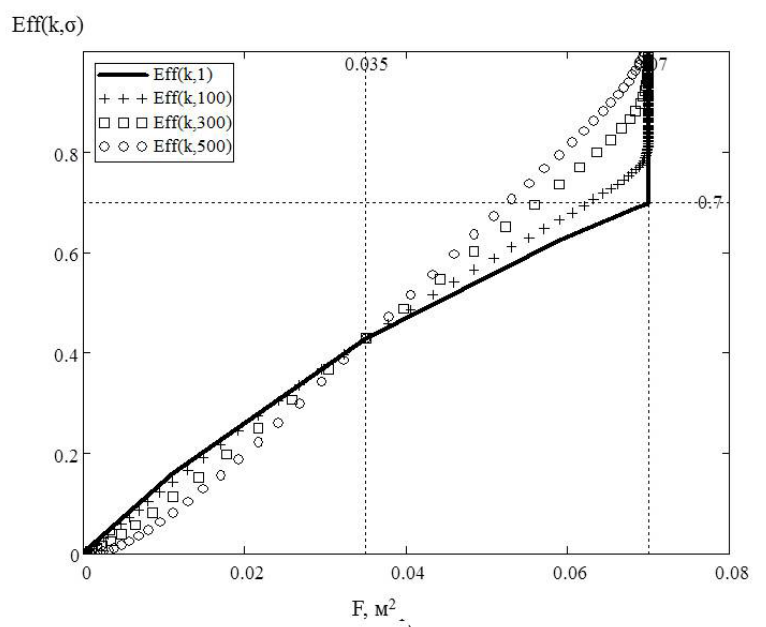

b)

Рис. 2. Графічне представлення характеру розподілу температур теплоносіїв $t_{1,2}(k, \sigma)$, теплового потоку $Q(k, \sigma)$ та ефективності $\mathrm{Eff}(k, \sigma)$ вздовюс теплообмінної гетерогенної поверхні $F(k, \sigma)$ в залежності від середньоквадратичного відхилення б.

На практиці, такий результат можна досягти за рахунок використання теплообмінної поверхні на базі широкого спектру матеріалів зі своїми теплообмінними властивостями - коефіцієнтами теплопередачі.

В табл. 1 продемонстровано один 3 можливих варіантів нормального розподілення коефіцієнтів теплопередачі вздовж гіпотетичної поверхні, який отриманий завдяки функції генерування випадкової величини в математичному пакеті MathCad [10]. Тут, зокрема, $F_{i}$ - частина загальної площі $F_{\text {Total }}$ зі своїм середнім коефіцієнтом теплопередачі $k_{i}$ в межах даної площі.
Користь даної таблиці полягає у тому, що вона відображає фізичну суть керування ефективністю теплообмінника в межах заданої величини $F$ за рахунок використання композитної теплообмінної поверхні. За згенерованою величиною $k_{i}$, згідно класичної формули для пласкої стінки, можна відшукати фізичні властивості теплопередавальної поверхні, зокрема, передбачити теплопровідність використовуваного матеріалу. Наприклад, розрахуємо коефіцієнт теплопровідності $i$-го компоненту теплопередавальної поверхні, у якої відомо: середній коефіцієнт теплопередачі: $\bar{k}_{i}=1056 \mathrm{BT} / \mathrm{M}^{2} \cdot \mathrm{K}$ (див. табл. 1); коефіцієнт тепло- 
віддачі зі сторони гарячого та холодного тепло- поверхні $\delta=25$ мм. носія: $\alpha_{1}=2,2 \cdot 10^{4}$ і $\alpha_{2}=7,9 \cdot 10^{3} \mathrm{BT} / \mathrm{M}^{2} \cdot \mathrm{K}$; товщина

Табл 1. Гаусове розподілення коефіцієнтів теплопередачі вздовж гіпотетичної поверхні

\begin{tabular}{|c|c|c|c|c|c|c|c|c|c|c|c|}
\hline$\sigma$ & $\begin{array}{c}\text { Фізичні } \\
\text { параметри }\end{array}$ & & & & & & & & & & \\
\hline \multirow{2}{*}{100} & $K, \mathrm{BT} / \mathrm{M}^{2} \cdot \mathrm{K}$ & 717,6 & 785,2 & 852,8 & 920,5 & 988,1 & 1056 & 1123 & 1191 & 1259 & 1326 \\
\hline & $F / F_{\text {Total }} \%$ & 0,23 & 1,73 & 5,87 & 14,5 & 24,47 & 25,43 & 16,97 & 7,87 & 2,57 & 0,37 \\
\hline \multirow{2}{*}{300} & $K_{i}, \mathrm{BT} / \mathrm{M}^{2} \cdot \mathrm{K}$ & 204,3 & 417,1 & 629,9 & 842,7 & $\underline{1056}$ & 1268 & 1481 & 1694 & 1907 & 2120 \\
\hline & $F / F_{\text {Total }}, \%$ & 0,53 & 2,4 & 8,5 & 17,67 & 27,27 & 24,27 & 14,2 & 4,2 & 0,8 & 0,17 \\
\hline
\end{tabular}

Тоді теплопровідність даного компоненту, згідно перетвореної формули [1-3, 9]:

$k_{i}=\left(\frac{1}{\alpha_{1}}+\frac{\delta}{\lambda_{i}}+\frac{1}{\alpha_{2}}\right)^{-1} \Rightarrow \lambda_{i}=\delta\left[\frac{1}{k_{i}}-\left(\frac{1}{\alpha_{1}}+\frac{1}{\alpha_{2}}\right)\right]^{-1},\left[\frac{\mathrm{BT}}{\mathrm{M} \cdot \mathrm{K}}\right]$,

дорівнює 32,3. Близьким до розрахованої теплопровідності матеріалом може бути, наприклад [11]: Ванадій V $(\lambda=30,7) ;$ Стронцій $\operatorname{Sr}(\lambda=$ $35,3)$; Свинець $\mathrm{Pb}(\lambda=35,3)$; сплав Нейзільбер $62 \% \mathrm{Cu} 15 \% \mathrm{Ni} 22 \% \mathrm{Zn} \quad(\lambda=31)$; Платиноірідій $90 \% \operatorname{Pt} 10 \% \operatorname{Ir}(\lambda=30,9-31)$ та інші. Аналогічним чином, розраховуються теплофізичні характеристики інших компонентів теплопередавальної поверхні, на базі яких відбувається підбір відповідних матеріалів і компонується нова теплообмінна площа із заданими теплофізичними властивостями.

\section{Висновки}

3 порівняльного аналізу двох теплообмінників, традиційного (гомогенного) і теплообмінника на базі композитної (гетерогенної) поверхні iз заданим законом розподілення коефіцієнтів теплопередачі вздовж поверхні теплообміну, очевидна перевага використання останнього. Якщо один і той же теплообмінник випробувати при однаковому включенні, то в другому випадку тепловий потік $Q$ виявиться залежною не тільки від величини середньо-інтегрального коефіцієнта теплопередачі $\bar{k}$, але й від величини розкиду коефіцієнтів теплопередачі $\sigma$ (чим вища величина $\sigma$ тим більший тепловий потік $Q$ i ефективність Eff - див. рисунок 2). Тому використання теплообмінників на базі композитної (гетерогенної) поверхні за схемою протитечії в більшості випадків слід розглядати як нове інженерне рішення, щодо можливості «програ- мувати» температурний профіль, тепловий потік та ефективність теплообмінника в межах заданої площі поверхні теплообмінну та температурного діапазону. Таким чином, в загальному балансі усіх теплофізичних змінних математичної моделі 3'являється новий параметр регулювання основними характеристиками теплообмінника. Зазначена вище можливість керувати температурною характеристикою відкриває перспективи створення компактних теплообмінників за рахунок підвищення ефективності і, відповідно, скорочення величини теплообмінної поверхні. Однак, необхідні додаткові оптимізаційні розрахунки щодо запропонованого інженерного рішення, щоби показати, чи виправдають додаткові витрати, пов'язані з використанням композитної поверхні, термодинамічним виграшом!?

\section{ЛІТЕРАТУРА}

1. Исаченко В.П., Осипова В.А., Сукомел А.С. Теплопередача. - М.: Энергия. - 1975. - 488c.

2. Каневец Г.Е. Обобщенные методы расчета теплообменников. -К.:Наук. думка. -1979. -352c. 3. Ильченко O.T. Тепло- и массообменные аппараты ТЭС и АЭС: Учеб. пособие. - К.: Вища шк. - 1992. - 207c.

4. Плановский А.Н., Рамм В.М., Каган С.3. Процессы и аппараты химической технологии. М.: Химия. - 1967. - 847c.

5. Brandner, J.J., Bohn, L., Henning, T., Schygulla, $U$., Schubert, $K$. Microstructure heat exchanger applications in laboratory and industry // Heat Transfer Engineering. - 2007. - 28 (8-9). - P. 761771.

6. Kraut, M., Wenka, A., Bohn, L., Schubert, K. 
Successful upscale of laboratory micro reactor into industrial scale // Proc. of the 6th ANQUE International Congress of Chemistry, Dec 5-7, 2006, Puerto de la Cruz, Tenerife, Spain, paper T2-L-9.

7. Kang S.W., Chen Y.T. and Chang G.S. The Manufacture and Test of (110) Orientated Silicon Based Micro Heat Exchanger // Tamkang Journal of Science and Engineering. - 2002. - Vol. 5, № 3. - P. 129-136.

8. Корн Г.А, Корн Т.М. Справочник по математике для научных работников и инженеров. - М.:
Наука. - 1974. - 832c.

9. Солодов А.П. Тепломассообмен в энергетических установках (электронный курс). http://twt.mpei.ac.ru/solodov/HMT-eBook_2009/ index.htm

10. Solodov A., Ochkov V. Differential Models: An Introduction with MathCAD. - Springer. - 2004. 246p.

11. Волков.А.И., Жарский. И.М. Большой химический справочник. - М.: Советская школа. $-2005 .-608$ c. 


\section{HEAT EXCHANGER RESEARCH WITH SPECIFY LAW DISTRIBUTION OF HEAT TRANSFER COEFFICIENTS ALONG THE HEAT TRANSFER SURFACE}

\section{Ievtushenko O.V.}

Institute of Engineering Thermophysics of the NAS of Ukraine, vul. Zhelyabova, 2a, 03680 Kyiv, Ukraine.

The paper considered heat exchanger in which the heat transfer coefficient varies along the heat transfer surface under the law of the normal Gaussian distribution. On the basis of the present heat exchanger is presented basic equations derivation in the form that convenient for the computational programs assembling and such that providing generalized to more complex systems. The necessary attention paid to the heat exchangers efficiency including the temperature distribution of heating / cooling heat carrier. The main conclusion of paper: in the total balance of all thermo-physics variables of the heat exchanger's mathematical model there is a new regulation parameter of the heat surface temperature profile that shows heat transfer coefficients variation along the heat transfer surface relative of the medium-integral value.

References 11, tables 1, figures 4.

Key words: central heating systems, coaxial pipe, tube-in-tube, heat transfer coefficient.

1. Isachenko V.P., Osipova V.A. Sukomel A.S. Heat transfer. - Moscow: Energiya. - 1975. - 488p. (Rus.)

2. Kanevets G.E. The generalized methods of heat exchangers calculation. - Kyiv: Nauk. Dumka. - 1979. - 352p. (Rus.)
3. Ichenko O.T. Heat and mass transfer devices TPP and NPP: Proc. allowance. - Kyiv: Vishcha shkola. - 1992. - 207p. (Rus.)

4. Planovskiy A.N., Ramm V.M., Kagan S.Z. Processes and apparatuses of chemical technology. Moscow: Himiya. - 1967. - 847p. (Rus.)

5. Brandner, J.J., Bohn, L., Henning, T., Schygulla, U., Schubert, K. Microstructure heat exchanger applications in laboratory and industry // Heat Transfer Engineering. - 2007. - 28 (8-9). P. 761-771.

6. Kraut, M., Wenka, A., Bohn, L., Schubert, $K$. Successful upscale of laboratory micro reactor into industrial scale // Proc. of the 6th ANQUE International Congress of Chemistry, Dec 5-7, 2006, Puerto de la Cruz, Tenerife, Spain, paper T2-L-9.

7. Kang S.W., Chen Y.T. and Chang G.S. The Manufacture and Test of (110) Orientated Silicon Based Micro Heat Exchanger // Tamkang Journal of Science and Engineering. - 2002. - Vol. 5, № 3. - P. 129-136.

8. Korn G.A., Korn T.M. Mathematical handbook for scientists and engineers. - Moscow: Nauka. - 1974. - 832p. (Rus.)

9. Solodov A.P. Heat and mass exchange in power machinery installations (Electronic Course). - http://twt.mpei.ac.ru/solodov/HMT-eBook_2009/ index.htm (Rus.)

10. Solodov A., Ochkov V. Differential Models: An Introduction with MathCAD. - Springer. - 2004. $-246 \mathrm{p}$.

11. Volkov.A.I., Zharskiy. I.M. The big chemical handbook. - Moscow: Sovetskaya shkola. - 2005. 608p. (Rus.)

Получено 15.10.2015 Received 15.10.2015 